\title{
Strain Induced by Bio-High-Performance Polymers and Cobalt-Chromium Digitally Constructed Telescopic Partial Dentures after 1 Year Simulation of Function
}

\author{
Mohammed Muwafi(D), Marwa Sabet (D), Yasmine Thabet (i) \\ Department of Oral and Maxillofacial Prosthodontics, Faculty of Dentistry, Ain Shams University, Cairo, Egypt
}

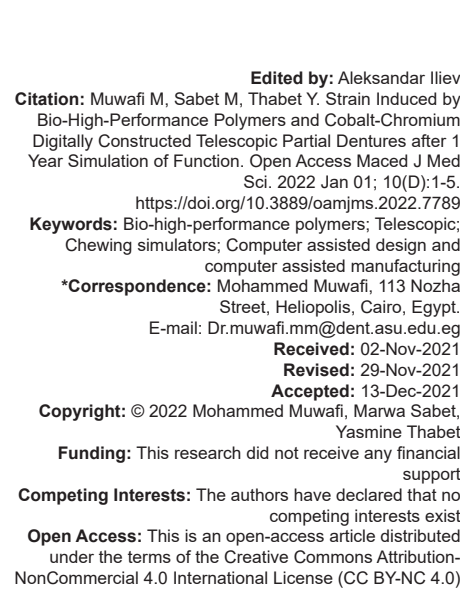

\section{Introduction}

Implant dentistry has evolved significantly in recent decades allowing different augmentation procedures or fabrication of custom-tailored implants to be produced specifically for the case. Anatomical constraints are becoming less important nowadays. However, these treatment modalities are expensive and involve multiple surgeries which might render them unsuitable for many patients. Hence, removable partial dentures (RPDs) continue to be viable treatment option for these cases. When RPDs are subjected to masticatory forces, the frameworks tend to rotate inevitably due the difference in the nature of the supporting structures. Thus, the abutments and the residual ridges are subjected to destructive loads [1].

Numerous attempts were made to reduce the adverse effects of the distal extension RPDs and enhance their prognosis. These trials included varying the retainer types, splinting the abutments, and incorporating new materials with a stress releasing property [2]

Telescopic retainers imparted the advantages of axial abutment loading, enhanced esthetics, and better load distribution when several abutments are splinted together. It also increased the maximum biting force and the quality of life compared to the conventional RPDs [3], [4].

Utilization of Bio-High-performance polymers (HPP) for fabrication of free end saddle RPD frameworks provides several advantages such as biocompatibility, resiliency, and esthetics. Bio-HPP frameworks help to buffer the stresses transmitted to the supporting structures and to reduce the torque directed to the abutments. However, due to the composite structure of these materials, polymers are subjected to wear when used to fabricate RPD retainers which adversely affects the retention of the prosthesis [5], [6], [7]. 
For distal extension cases where telescopic retainers are implemented, accurate manufacturing is a prerequisite to enhance the features provided by the retainer. The conventional manufacturing methods using the lost wax technique, suffer from inherent inaccuracies arising from either human errors or material deficiencies [8].

The use of computer assisted design and computer assisted manufacturing (CAD/CAM), to construct RPD frameworks could be beneficial in terms of accuracy, precision, and reproducibility. Few studies have investigated the qualities of the CAD/CAM fabricated RPDs; thus, this study was prompted to compare the strain values induced on the abutments and the distal aspect of the residual ridge, by Bio-HPP and Co-Cr CAD/CAM telescopic RPDs after 1 year of function [9], [10]. The null hypothesis was that there was no difference in the strain values induced by Bio-HPP and $\mathrm{Co}-\mathrm{Cr}$ telescopic RPDs on the abutments and the distal aspect of the residual ridge after 1 year of function.

\section{Materials and Methods}

An in vitro study was applied on a maxillary educational model with bilateral free end edentulous areas (Kennedy class I). The drill press machine (Nouvag Headquarters, 9403 Goldach - Switzerland) was used for reduction of the canines and first premolars bilaterally. The amount of reduction $(2-3 \mathrm{~mm})$ was verified by a rubber mold (Dental Products 3M Center Building 275-2SE-03 St. Paul, MN 55144-1000 USA). A clear vacuum formed stent was pressed on the cast. Then, the model was scanned using the 3D desktop scanner (3Shape D850) (3Shape A/S, Holmens Kanal 7, 1060 Copenhagen K Denmark).

The Model Creator module of Exocad (Exocad $\mathrm{GmbH}$ ) and the Meshmixer (Autodesk.Inc) were used to convert the prepared abutments into removable dies with $0.2 \mathrm{~mm}$ PDL space. The saddle areas were depressed $1.5 \mathrm{~mm}$ to create a space for the tissue simulating material. A slice was cut $1 \mathrm{~mm}$ distal to the first premolars bilaterally and $0.2 \mathrm{~mm}$ depressions were created at the second molar area for the strain gauge sensors. $\left(1.5^{\star} 3 \mathrm{~mm}\right)$

The modified virtual models and dies were 3D printed (Dent 2, 3D printer (C) 2019 Mogassam Co.) using model resin (NextDent B.V. Centurionbaan 190 | 3769 AV Soesterberg | The Netherlands) (Figure 1).

Twelve sets of dies and models were printed to be used for fabrication of twelve telescopic RPDs from two different materials. Hence, two groups were identified. In Group A, six telescopic RPDs were milled from Cobalt- Chromium (Co-Cr) and in Group B, six telescopic RPDs were milled from Bio-HPP.

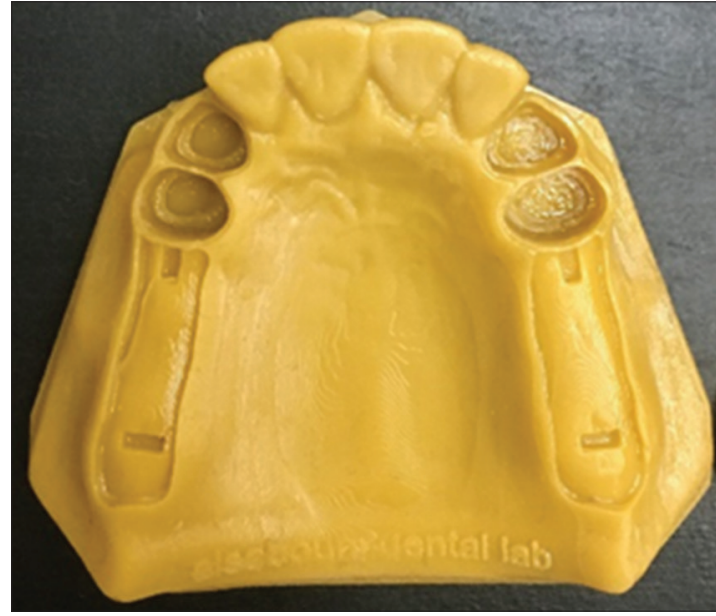

Figure 1:3D Printed cast after modification of the educational model

Soft tissue simulating material (Multisil-Mask soft Assortment, bredent $\mathrm{GmbH}$ \& Co.KG) was applied onto the printed models using the clear vacuum formed stent to simulate the mucosa and the PDL, guided by the remaining teeth and the palate.

The primary telescopic copings were designed using the partial denture module of Exocad (Exocad $\mathrm{GmbH}$ ) to conform to the Murburg double crown system design with an apical parallel band of $1.5-2 \mathrm{~mm}$ vertical height between the finish line and conical coronal portions. The conical part was tapered $6^{\circ}$ axially [3]. The STL file of the virtual cast with the primary copings was used to design the secondary telescopic copings which were splinted together. $1.2 \mathrm{~mm}$ surface reduction of the facial surface of the secondary crowns was done to create a space for the esthetic veneering material. The RPDs frameworks were designed following the conventional design principles (Figure 2).

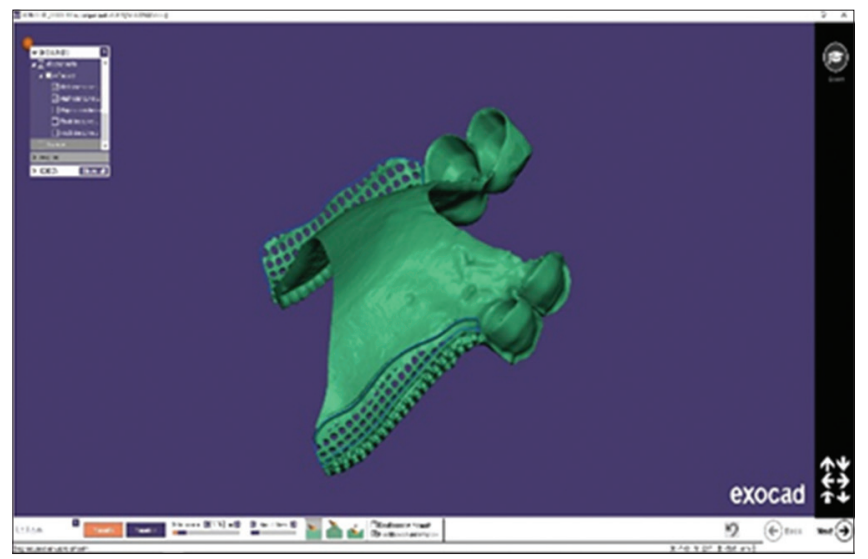

Figure 2: Finalized digital design of the telescopic partial dentures

The primary copings and the frameworks were milled using COR I-TEC 350i Loader PRO (imes- icore ® $\mathrm{GmbH}, 16$ Leibolzgraben, 36132 Eiterfeld, Germany.). In Group A, they were milled from fully sintered $\mathrm{Co}-\mathrm{Cr}$ discs (c (MESA DI SALA GIACOMO \& C. S.N.C., Via dell'Artigianato, 35/37/39 - 25039 Travagliato (BS) ITALY.) while in Group B, they were milled from Bio-HPP10 (@) bredent UK 2020). 
Each primary coping was cemented to the corresponding removable die (abutment tooth) using glass ionomer cement, Medicem (Promedica Dental Material $\mathrm{GmbH}$ ). Then, each framework was seated to verify the fit on the corresponding removable dies.

A rubber index mold (Dental Products $3 \mathrm{M}$ Center Building 275-2SE-03 St. Paul, MN 55144-1000 USA) was made on the waxed-up partial denture to standardize the position of the teeth (Polident d.o.o. Dental Products Industry. Volčja Draga 42, Slovenija) in both groups and teeth were attached to the frameworks with self-cure acrylic resin (Polident d.o.o. Dental Products Industry. Volčja Draga 42, Slovenija). Esthetic veneering of the retainers was done using Visiolin (C) bredent UK 2020).

Each partial denture was seated on the cast with the corresponding set of dies with the primary copings and introduced into the chewing simulator (Robota, Chewing Simulator with Thermocycle). A series of 240,000 biaxial loading cycles were conducted to simulate the function of the partial denture for 1 year (Figure 3).

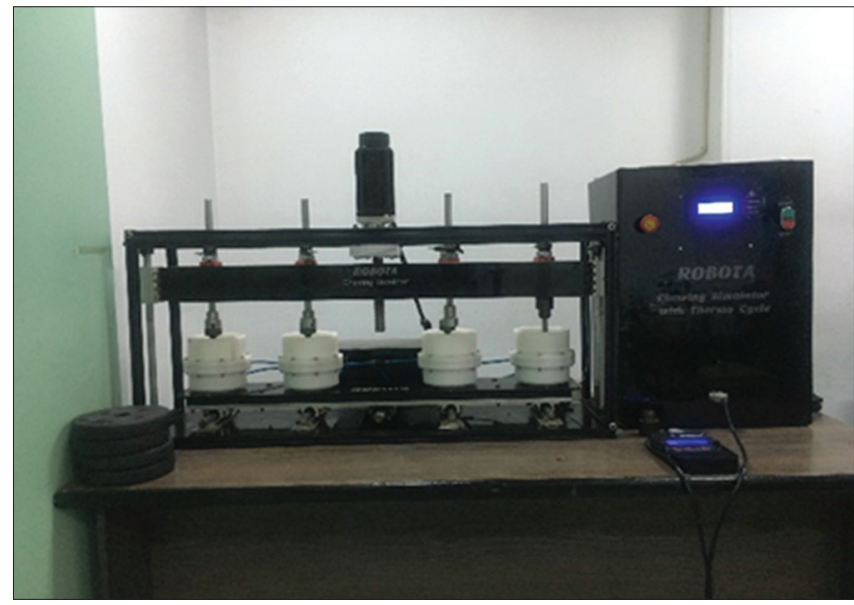

Figure 3: The frameworks seated on the casts and introduced into the chewing simulator

Four strain gauge sensors (Strain gauges Kyowa-Electronic Instruments Co, LTD, Tokyo, Japan.) of $3 \mathrm{~mm}$ length, electric resistance $119.6 \pm 0.4 \Omega$, and gauge factor $2.1 \pm 1.0 \%$ were installed at the predetermined sites with cyano-acrylate adhesive (@2016 Permabond LLC.). For each cast, universal testing machine LD Series (bench mounted, (C2015 AMETEK. Inc.) was used to apply a static load of $100 \mathrm{~N}$ bilaterally at the first molar then unilaterally on the right side. The strain was recorded using four strain gauges connected to a four-channel strain indicator. (Strainmeter PCD-300A Kyowa-Electronic Instruments Co, LTD, Tokyo, Japan.). The load was applied 6 times to each partial denture (Figure 4).

The $G$ power software for windows version 3.1.9.4 was used to calculate the sample size. The results were recorded and statistically analyzed. Numerical data were presented by mean and standard deviation (SD). One-way ANOVA, followed by Tukey's HSD multiple

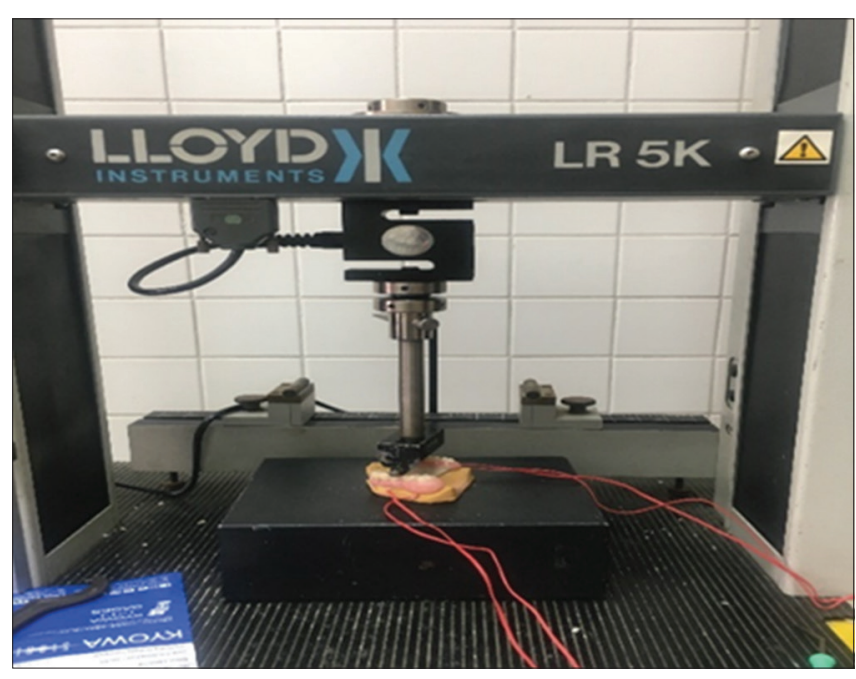

Figure 4: Universal testing machine

comparison tests were used to compare between different strain values within the same group. Student t-test was used for comparison between the different groups. The significance level was set at $p \leq 0.05$.

\section{Results}

Regarding bilateral loading, higher strains were recorded in Group A (Co Cr) $492.5 \mu \mathrm{m} / \mathrm{m} \pm 58.68$ and $194.17 \mu \mathrm{m} / \mathrm{m} \pm 34.37$ at the abutments and the distal aspect of the ridges, respectively. On the other hand, the strains induced in Group B (BioHPP) were $120 \mu \mathrm{m} / \mathrm{m} \pm 11.48$ at the abutments and $44.08 \mu \mathrm{m} / \mathrm{m} \pm 7.57$ at the distal aspect of the ridges. These differences were statistically significantly $(t=21.58, p \leq 0.0001)$ and $(t=14.77, p \leq 0.0001)$ (DOF $=22$ ) for the abutments and ridges, respectively, denoting higher stresses induced in Group A (Table 1).

Table 1: Mean, standard deviation, $t$ value and $P$ value for independent t-test under bilateral loading

\begin{tabular}{|c|c|c|c|c|c|c|c|c|}
\hline \multirow[t]{2}{*}{ Groups } & \multicolumn{2}{|c|}{ Group A (Co-Cr) } & \multicolumn{2}{|c|}{ Group B (Bio-HPP) } & \multicolumn{2}{|c|}{$\begin{array}{l}95 \% \text { confidence } \\
\text { interval }\end{array}$} & \multirow[t]{2}{*}{$\mathrm{t}$-value } & \multirow[t]{2}{*}{$p$-value } \\
\hline & Mean & SD & Mean & SD & lower & upper & & \\
\hline Abutment & 492.5 & 58.68 & 120 & 11.48 & 336.7 & 408.3 & 21.58 & $<0.0001$ \\
\hline Ridge & 194.17 & 34.37 & 44.08 & 7.57 & 129.02 & 171.15 & 14.71 & $<0.0001$ \\
\hline
\end{tabular}

During unilateral load application, there were higher strains on the loaded abutment and ridge $(473.33 \mu \mathrm{m} / \mathrm{m} \pm 10.80),(470.83 \mu \mathrm{m} / \mathrm{m} \pm$ 13.93) in Group $A$, and $(62.5 \mu \mathrm{m} / \mathrm{m} \pm 9.35)$, $(93.33 \mu \mathrm{m} / \mathrm{m} \pm 11.25)$ in Group B. Lower strains were recorded at the unloaded abutments and ridges (193.33 $\mu \mathrm{m} / \mathrm{m} \pm 10.8),(185 \mu \mathrm{m} / \mathrm{m} \pm 10.4)$ for Group $A$ and $(20.83 \mu \mathrm{m} / \mathrm{m} \pm 3.76),(20.83 \mu \mathrm{m} / \mathrm{m} \pm 4.9)$ for Group (B). One-way ANOVA was used in each group, and it showed $(F=1191.8, p \leq 0.00001)$ for Group $A$ and $(F=118.3, p \leq 0.00001)$ for Group $B$ and the results was statistically significant. However, using Tukey's 
Table 2: Mean, standard deviation, $F$ ratio, and $p$-value for ANOVA test of strains under unilateral loading in both groups

\begin{tabular}{|c|c|c|c|c|c|c|c|c|c|c|}
\hline \multirow[t]{2}{*}{ Sites } & \multicolumn{2}{|c|}{ Loaded abutment } & \multicolumn{2}{|c|}{ Loaded ridge } & \multicolumn{2}{|c|}{ Unloaded Abutment } & \multicolumn{2}{|c|}{ Unloaded ridge } & \multirow[t]{2}{*}{ F ratio } & \multirow[t]{2}{*}{$\mathrm{p}$-value } \\
\hline & Mean & SD & Mean & SD & Mean & SD & Mean & SD & & \\
\hline Group A & $473.33 a$ & 10.80 & $470.83 \mathrm{~A}$ & 13.93 & 193.33B & 10.8 & $185 B$ & 10.488 & 1191.8 & $\leq 0.00001$ \\
\hline Group B & $62.5 a$ & 9.35 & $93.33 \mathrm{~B}$ & 11.25 & $20.83 C$ & 3.76 & $20.83 C$ & 4.9 & 118.30 & $\leq 0.00001$ \\
\hline
\end{tabular}

*Different letters stand for significance after Tukey's HSD post hook test.

HSD as a post hook test in Group A, there was a statistically significant difference between the loaded and unloaded side while there was no statistically significant difference between the abutments and the distal aspect of the ridge on the same side. On the other hand, in Group B, Tukey's HSD showed statistically significant difference between the loaded and unloaded sides (abutments and ridge) and between the abutment and the ridge on the loaded side. However, there was statistically insignificant difference between the abutments and the ridge on the unloaded side (Table 2).

In comparison between the two groups during unilateral loading, the results showed higher strains values in Group $A$ at the abutments $(473.33 \mu \mathrm{m} / \mathrm{m} \pm 10.8,193.33 \mu \mathrm{m} / \mathrm{m} \pm 10.8)$ and at the distal aspect of the ridge $(470.83 \mu \mathrm{m} / \mathrm{m} \pm 13.93$, $185 \mu \mathrm{m} / \mathrm{m} \pm 20.83)$ than Group B which showed $(62.5 \mu \mathrm{m} / \mathrm{m} \pm 9.35,20.83 \pm 3.76)$ at the abutments and $(93.33 \mu \mathrm{m} / \mathrm{m} \pm 11.25,20.83 \mu \mathrm{m} / \mathrm{m} \pm 4.93)$ at the distal aspect of the ridge. On using independent $\mathrm{t}$-test, it was found that $(\mathrm{t}=70.42, \mathrm{p} \leq 0.0001)$ for the loaded abutment, $(t=36.84, p \leq 0.0001)$ for the unloaded abutment. While $(t=551.62, p \leq 0.0001)$ for the loaded saddle and $(t=34.72, p \leq 0.0001)$ for the unloaded saddle (DOF $=10)$. These differences were statistically significant (Table 3 ).

Table 3: Mean, standard deviation, $\mathrm{Cl}$, t-values, and $\mathrm{p}$-value for independent t-test for comparison between the two groups under unilateral loading

\begin{tabular}{|c|c|c|c|c|c|c|c|c|}
\hline \multirow[t]{2}{*}{ Sites } & \multicolumn{2}{|c|}{ Group A (Co-Cr) } & \multicolumn{2}{|c|}{$\begin{array}{l}\text { Group B } \\
\text { (Bio-HPP) }\end{array}$} & \multicolumn{2}{|c|}{$\begin{array}{l}95 \% \text { confidence } \\
\text { interval }\end{array}$} & \multirow[t]{2}{*}{ t values } & \multirow[t]{2}{*}{$p$-value } \\
\hline & Mean & SD & Mean & SD & Lower & Upper & & \\
\hline $\begin{array}{l}\text { Loaded } \\
\text { abutments }\end{array}$ & 473.33 & 10.8 & 62.5 & 9.35 & -423.83 & -397.84 & 70.42 & $\leq 0.0001$ \\
\hline $\begin{array}{l}\text { Unloaded } \\
\text { abutments }\end{array}$ & 193.33 & 10.8 & 20.83 & 3.76 & -182.9 & -162.10 & 36.84 & $\leq 0.0001$ \\
\hline $\begin{array}{l}\text { Loaded side } \\
\text { saddle }\end{array}$ & 470.83 & 13.93 & 93.33 & 11.25 & -393.79 & -361.21 & 51.62 & $\leq 0.0001$ \\
\hline $\begin{array}{l}\text { Unloaded } \\
\text { side saddle }\end{array}$ & 185 & 10.94 & 20.83 & 4.92 & -174.7 & -153.63 & 34.72 & $\leq 0.0001$ \\
\hline
\end{tabular}

\section{Discussion}

During function, distal extension RPDs are subjected to multidirectional forces that lead to rotation of the prosthesis due to the viscoelastic nature of the supporting structures. Rotation of the RPDs leads to resorption of the ridges and creates torque on the abutments [11].

Thus, this in vitro study was conducted to evaluate the effect of using the chewing simulating device on strain values induced by telescopic retained RPDs at the abutments and the distal aspect of the ridge after 1 year in function.

Telescopic retained RPDs splint the abutments, direct the forces along the long axis of the abutments and decrease the degree of rotation of the prosthesis. The abutment teeth were reduced by $2 \mathrm{~mm}$ to allow circumferential clearance to accommodate the thickness of the primary and secondary telescopic copings [12].

Nextdent model resin was used to print the model because it has adequate mechanical properties to withstand the stresses applied during loading. Soft tissue simulating material, was injected into the PDL space and the modified saddles to ensure a natural stress pattern during loading [13]. Twelve models were fabricated to avoid distortion of the mucosa simulating material during application of the chewing simulation device.

The primary and secondary copings were designed with the minimum thickness that provides adequate mechanical properties required for function. Additional surface reduction of the secondary copings was done to create space for the visiolign to simulate the final prosthesis [7], [14].

The results of the study showed that during unilateral and bilateral loading, group B (Bio-HPP) induced less strain values on the abutments and the distal aspect of the ridge. This may be attributed to the reduced modulus of elasticity of Bio-HPP (4GPa). This results in a cushioning effect reducing the stresses transmitted to the supporting structures [15], [16], [17].

The results agree with a previous study that stated that PEEK frameworks induced lower stress values on the periodontal ligament than $\mathrm{CoCr}$ and $\mathrm{Ti}$ alloys. Thus, PEEK RPDs were recommended for patients with poor periodontal conditions [18], [19].

During unilateral load application, strain was concentrated at the distal aspect of the ridge at the loaded side rather than distributed between the abutment and the saddle in group B (Bio-HPP). The increased resiliency of the Bio-HPP may be the cause of stress concentration at the distal aspect of the ridge. These results coincide with a study that reported that PEEK caused the highest stresses and the greatest displacement at the free-end area and suggested that it should be used with caution in distal extension RDPs [20], [21].

In Group A ( $\mathrm{CoCr}$ ), there was no significant difference between the strain values recorded at the abutments and the distal aspect of the ridge. This may be attributed to the rigidity of the major connector that 
allows stresses to be evenly distributed over the entire supporting area [22].

\section{Conclusions}

Within the limitations of this study, the following could be concluded:

\section{- In telescopic RPDs, Co Cr induces higher strain values at the abutments and the distal aspect of the ridge than Bio-HPP during bilateral and unilateral loading. \\ - $\quad$ During unilateral loading, Bio-HPP telescopic RPDs direct high strain values at the distal aspect of the ridge of the loaded side.}

\section{References}

1. Ramchandran A, Agrawal KK, Chand P, Ramashanker, Singh RD, Gupta A. Implant-assisted removable partial denture: An approach to switch Kennedy Class I to Kennedy Class III. J Indian Prosthodont Soc. 2016;16(4):408-11. https://doi. org/10.4103/0972-4052.179262

PMid:27746609

2. McCord JF, Grey NJ, Winstanley RB, Johnson A. A clinical overview of removable prostheses: 3 . Principles of design for removable partial dentures. Dent Update. 2002;29(10):474-81. https://doi.org/10.12968/denu.2002.29.10.474 PMid:12572192

3. Hakkoum MA, Wazir G. Telescopic denture. Open Dent J. 2018;12:246-54. https://doi. org/10.2174/1874210601812010246 PMid:29760817

4. Akinyamoju CA, Dosumu OO, Taiwo JO, Ogunrinde TJ, Akinyamoju AO. Oral health-related quality of life: Acrylic versus flexible partial dentures. Ghana Med J. 2019;53(2):163-9. https://doi.org/10.4314/gmj.v53i2.12

PMid:31481813

5. Katzer A, Marquardt H, Westendorf J, Wening JV, von Foerster G Polyetheretherketone--cytotoxicity and mutagenicity in vitro. Biomaterials. 2002;23(8):1749-59. https://doi.org/10.1016/ s0142-9612(01)00300-3

PMid: 11950045

6. Bathala L, Majeti V, Rachuri N, Singh N, Gedela S. The role of polyether ether ketone (Peek) in dentistry a review. J Med Life. 2019;12(1):5-9. https://doi.org/10.25122/jml-2019-0003 PMid:31123518

7. Alexakou E, Damanaki M, Zoidis P, Bakiri E, Mouzis N, Smidt G, et al. PEEK high performance polymers: A review of properties and clinical applications in prosthodontics and restorative dentistry. Eur J Prosthodont Restor Dent. 2019;27(3):113-21. https://doi.org/10.1922/EJPRD_01892Zoidis09 PMid:31433133

8. Arnold C, Hey J, Schweyen R, Setz JM. Accuracy of CADCAM-fabricated removable partial dentures. J Prosthet Dent. 2018;119(4):586-92. https://doi.org/10.1016/j. prosdent.2017.04.017

\section{PMid:28709674}

9. Kim JJ. Revisiting the removable partial denture. Dent Clin North Am. 2019;63(2):263-78. https://doi.org/10.1016/j. cden.2018.11.007

PMid:30825990

10. Harb IE, Abdel-Khalek EA, Hegazy SA. CAD/CAM constructed poly(etheretherketone) (PEEK) framework of Kennedy Class I removable partial denture: A clinical report. J Prosthodont. 2019;28(2):e595-8. https://doi.org/10.1111/jopr.12968 PMid:30345575

11. Cehreli MC, Iplikçioglu $\mathrm{H}$. In vitro strain gauge analysis of axial and off-axial loading on implant supported fixed partial dentures. Implant Dent. 2002;11(3):286-92.

PMid:12271568

12. Yildiz C, Vanlioğlu BA, Evren B, Uludamar A, Ozkan YK Marginal-internal adaptation and fracture resistance of CAD/ CAM crown restorations. Dent Mater J. 2013;32(1):42-7. https:// doi.org/10.4012/dmj.2012-148

PMid:23370869

13. Revilla-León M, Meyers MJ, Zandinejad A, Özcan M. A review on chemical composition, mechanical properties, and manufacturing workflow of additively manufactured current polymers for interim dental restorations. J Esthet Restor Dent. 2019;31(1):51-7. https://doi.org/10.1111/jerd.12438 PMid:30367716

14. Kirsch C, Ender A, Attin T, Mehl A. Trueness of four different milling procedures used in dental CAD/CAM systems. Clin Oral Investig. 2017;21(2):551-8. https://doi.org/10.1007/ s00784-016-1916-y PMid:27469100

15. Stawarczyk B, Eichberger M, Uhrenbacher J, Wimmer T, Edelhoff D, Schmidlin PR. Three-unit reinforced polyetheretherketone composite FDPs: Influence of fabrication method on load-bearing capacity and failure types. Dent Mater J. 2015;34(1):7-12. https://doi.org/10.4012/dmj.2013-345 PMid:25311236

16. Hill EE, Rubel B, Smith JB. Flexible removable partial dentures: A basic overview. Gen Dent. 2014;62(2):32-6. PMid:24598492

17. Iyer R, Suchitra SR, Hegde D, Coutinho CA, Priya A. BIOHPP Properties and applications in prosthodontics a review. J Res Dent. 2019;7(4):72-6. http://dx.doi.org/10.19177/jrd. v7e4201972-76

18. Papathanasiou I, Kamposiora P, Papavasiliou G, Ferrari M The use of PEEK in digital prosthodontics: A narrative review. BMC Oral Health. 2020;20(1):217. https://doi.org/10.1186/ s12903-020-01202-7 PMid:32741366

19. Zoidis P, Papathanasiou I, Polyzois G. The use of a modified poly-ether-ether-ketone (PEEK) as an alternative framework material for removable dental prostheses. A clinical report. J Prosthodont 2016;25(7):580-4. https://doi.org/10.1111/ jopr.12325 PMid:26216668

20. Stewart KL, Rudd KD, Kuebker WA. Clinical Removable Partial Prosthodontics. $2^{\text {nd }}$ ed. St. Louis: CV Mosby; 2000.

21. Schwitalla AD, Spintig T, Kallage I, Müller WD. Flexura behavior of PEEK materials for dental application. Dent Mater. 2015;31(11):1377-84. https://doi.org/10.1016/j.dental.2015.08.151 PMid:26361808

22. Bohnenkamp DM. Removable partial dentures: Clinical concepts. Dent Clin North Am. 2014;58(1):69-89. https://doi. org/10.1016/j.cden.2013.09.003

PMid:24286646 